\title{
Experienced Scuba Divers in Australia and the United States Suffer Considerable Injury and Morbidity
}

\author{
David McD. Taylor, MD, FACEM; Kevin S. O’Toole, MD; Christopher M. Ryan, PhD \\ From the Royal Melbourne Hospital, Victoria, Australia (Dr Taylor); and the Department of Emergency Medicine (Dr O'Toole), and \\ Western Psychiatric Institute \& Clinic (Dr Ryan), University of Pittsburgh, Pittsburgh, PA.
}

\begin{abstract}
Objective.-Scuba diving-specific injuries have been well described. However, the injury experiences of individual divers over long diving careers have rarely been investigated. Our objective was to study the acute and chronic injuries of experienced, recreational scuba divers.

Methods.-This was an international, cross-sectional, descriptive postal survey of experienced, recreational scuba divers belonging to diving clubs in Australia and the United States.

Results.- Seven hundred nine divers were enrolled (346 Australian divers and 363 US divers). Most participants were experienced (mean number of dives, 262) male divers (488; 68.8\%) aged 31 to 50 years $(425 ; 59.9 \%)$. Mild barotrauma was common. Ear, sinus, and tooth "squeeze" had been experienced on $\geq 1$ occasion by 369 (52.1\%), 245 (34.6\%), and 66 (9.2\%) divers, respectively. Tympanic membrane (TM) rupture, round/oval window rupture, and subcutaneous emphysema had been experienced by $38(5.4 \%), 8(1.1 \%)$, and $5(0.7 \%)$ divers, respectively. No diver reported pneumothorax or arterial gas embolism (AGE); however, 31 divers (4.4\%) had suffered decompression sickness (DCS). A wide range of other injuries were reported. Sixteen divers $(2.3 \%)$ reported permanent disabilities, which largely consisted of hearing loss, tinnitus, and balance disorder.

Conclusions.- The majority of experienced divers who responded to the survey had suffered diving-related injuries, mainly barotrauma. Further research and diver education are needed to better document injury rates and minimize serious diving-related injuries and permanent disabilities.
\end{abstract}

Key words: scuba, diver, injury, accident, morbidity

\section{Introduction}

Recreational scuba diving is one of the fastest growing leisure sports. ${ }^{1}$ It is estimated that there are almost 9 million certified divers in the United States alone. ${ }^{2}$ Diving has often been described as a high-risk sport. ${ }^{3-5}$ Edmonds ${ }^{6}$ quotes international reports of death rates among recreational divers ranging from 15 to 20 deaths per 100000 divers. In the United States, fatalities have occurred at an average rate of 90 per year since $1980 .^{2}$

Diving-specific acute injuries, including decompression sickness (DCS) and the various forms of barotrauma, have been well described. ${ }^{4,7,8}$ Specific chronic effects of diving, including dysbaric osteonecrosis and residual deficit following clinical DCS and arterial gas embolism (AGE), have also been reported. ${ }^{9,10}$ However,

Corresponding author: David McD. Taylor, MD, FACEM, Director of Emergency Medicine Research, Emergency Department, Royal Melbourne Hospital, Grattan St, Parkville, Victoria, Australia 3050 (e-mail: david.taylor@mh.org.au). there is now increasing evidence that divers may suffer subclinical pathological deficits even in the absence of a history of clinical DCS or other diving accidents. ${ }^{9-11}$ Reul et $\mathrm{al}^{11}$ found that divers had significantly more hyperintense lesions of the subcortical cerebral white matter (on magnetic resonance imaging) than controls. They concluded that long-term amateur diving may cause central nervous system (CNS) degeneration even if DCS incidents have not occurred.

Although the exact mechanism of this degeneration remains unclear, subclinical DCS is possible. It has been postulated that repeated liberation of silent bubbles in divers can result in permanent damage, especially to the CNS. ${ }^{11}$ Another possibility was suggested by Knauth et al. ${ }^{12}$ They found multiple brain lesions in sports divers that were associated with a large patent foramen ovale and suggested that paradoxical gas embolism was one pathological mechanism. Regardless of the exact mechanism, a repeated exposure to the hyperbaric environment and the breathing of compressed gas for prolonged 
Table 1. Demographic data for the divers (percentages in parentheses)

\begin{tabular}{|c|c|c|c|}
\hline & $\begin{array}{c}\text { Australian } \\
\text { divers }\end{array}$ & US divers & Total \\
\hline \multicolumn{4}{|l|}{ Gender } \\
\hline Male & $253(35.7)$ & $235(33.2)$ & $488(68.8)$ \\
\hline Female & $92(13.0)$ & $124(17.5)$ & $216(30.5)$ \\
\hline No answer & $1(0.1)$ & $4(0.6)$ & $5(0.7)$ \\
\hline \multicolumn{4}{|l|}{ Age (y) } \\
\hline $18-20$ & $10(1.4)$ & $6(0.9)$ & $16(2.3)$ \\
\hline $21-30$ & $72(10.2)$ & $20(2.8)$ & $92(13.0)$ \\
\hline $31-40$ & $120(16.9)$ & $73(10.3)$ & $193(272)$ \\
\hline $41-50$ & $85(12.0)$ & $147(20.7)$ & $232(32.7)$ \\
\hline $51-60$ & $53(7.5)$ & $90(12.7)$ & $143(20.2)$ \\
\hline$>60$ & $6(0.9)$ & $21(3.0)$ & $27(3.9)$ \\
\hline No answer & $0(0)$ & $6(0.9)$ & $6(0.9)$ \\
\hline \multicolumn{4}{|l|}{ Occupation } \\
\hline Unemployed & $24(3.4)$ & $16(2.3)$ & $40(5.7)$ \\
\hline Blue collar/trade & $105(14.8)$ & $60(8.5)$ & $165(23.3)$ \\
\hline White collar/clerical & $54(7.6)$ & $48(6.8)$ & $102(14.4)$ \\
\hline Professional & $153(21.6)$ & $236(33.3)$ & $389(54.9)$ \\
\hline No answer & $10(1.4)$ & $3(0.4)$ & $13(1.8)$ \\
\hline Totals & $346(48.8)$ & $363(51.2)$ & $709(100)$ \\
\hline
\end{tabular}

periods may cause impaired physical and psychological health. ${ }^{10}$ This impairment may or may not be noticeable to the individual.

Most reports of diving injury have concentrated on acute injuries. Chronic disabilities have been less well reported and are usually related to the immediate consequences of acute events. This study investigated the acute and chronic injuries suffered by experienced, recreational divers during long diving careers. The results shed light on the nature and risk of injuries that can be expected by such divers and will help direct research and intervention strategies aimed at reducing these injuries.

\section{Methods}

The study was a cross-sectional, descriptive, postal survey of Australian and US scuba diving club members. Clubs and their representatives (presidents or secretaries) were identified from lists published on the Internet. Forty-eight Australian and 50 US club representatives were contacted (by telephone or e-mail) to obtain consent for their club's participation.

In June 2000, each club's representative was mailed a variable number of study questionnaires, depending on the number of active members. These were distributed at the next club meeting, completed immediately, and returned by the representative in a stamped, addressed envelope. Two months after the initial mailing, clubs that had not returned questionnaires were mailed a reminder letter; if necessary, this process was repeated 1 month later. Participation was voluntary, and responses were confidential. Club representatives were requested to complete a form reporting the total number of members at their meeting. This number (and the number of questionnaires completed) would allow a response rate calculation.

The questionnaire was developed by 2 investigators and evaluated for face and context validity. It collected demographic data, diving experience, and data on acute injuries and chronic disabilities resulting from diving over the duration of the divers' careers. To collect injury data, the divers were asked to indicate the number of times they had sustained diving-related injuries listed on the questionnaire. Details of chronic disabilities were obtained from an open-ended question. Most responses were analyzed descriptively. Where acute injuries were reported, injury rates (injuries per 1000 dives, 95\% CIs) were calculated by Epicalc, version 1.02 (2000). For the calculation of injury rates, divers were deemed to have suffered the injury on only 4 occasions if they checked the "many times" option. For comparisons of proportions, chi-square analysis was performed by the STATA statistical package (Intercooled, version 7.0, College Station, TX).

This study represents one arm of a larger study that investigated the physical and psychological health of experienced scuba divers. The larger study was authorized by the Institutional Review Board (Ethics Committee) of the University of Pittsburgh, Pittsburgh, PA.

\section{Results}

Twenty-nine Australian and 28 United States clubs participated by returning completed questionnaires. These clubs were spread widely across both countries and included both inland and coastal areas. A total of 709 divers responded (346 Australian divers and 363 US divers), and their demographic data are described in Table 1. The majority of divers were men aged 31 to 50 years. The US divers were significantly older $\left(\chi^{2}=82.0, d f\right.$ $=6, P<.001)$, with 258 of the divers $(71.1 \%)$ older than 40 years compared to 144 of the divers $(41.7 \%)$ in the Australian group. The majority of divers were professionally employed. Overall, the respondents were experienced scuba divers and reported having undertaken a combined total of 182951 dives. The mean number of years of diving was 10.7 (median, 8; range, 0-50), and 
Table 2. Diving-related injuries sustained by the divers $(n=709)$

\begin{tabular}{|c|c|c|c|c|c|c|c|}
\hline \multirow[b]{2}{*}{ Injury } & \multicolumn{6}{|c|}{ No. of times injury sustained (percentages in parentheses) } & \multirow{2}{*}{$\begin{array}{c}\text { Injury rate } \\
\text { per } 1000 \text { Dives } \\
(95 \% \text { CIs })\end{array}$} \\
\hline & Never & Once & Twice & $\begin{array}{c}\text { Three } \\
\text { times }\end{array}$ & $\begin{array}{l}\text { Many } \\
\text { time }\end{array}$ & $\begin{array}{c}\text { No } \\
\text { answer }\end{array}$ & \\
\hline \multicolumn{8}{|l|}{ Squeeze } \\
\hline Ear & $330(46.5)$ & $99(14.0)$ & $43(6.1)$ & $50(7.1)$ & $177(25.0)$ & $10(1.4)$ & $5.7(5.4,6.1)$ \\
\hline Sinus & $449(63.3)$ & $72(10.2)$ & $51(7.2)$ & $31(4.4)$ & $91(12.8)$ & $15(2.1)$ & $3.8(3.6,4.1)$ \\
\hline Tooth & $628(88.6)$ & $37(5.2)$ & $10(1.4)$ & $6(0.8)$ & $13(1.8)$ & $15(2.1)$ & $0.7 \quad(0.6,0.8)$ \\
\hline Tympanic membrane rupture & $662(93.4)$ & $21(3.0)$ & $3(0.4)$ & $0(0)$ & $14(2.0)$ & $9(1.3)$ & $0.5 \quad(0.4,0.6)$ \\
\hline Round/oval window rupture & $677(95.5)$ & $8(1.1)$ & $0(0)$ & $0(0)$ & $0(0)$ & $24(3.4)$ & $0.04(0.01,0.07)$ \\
\hline Subcutaneous emphysema & $683(96.3)$ & $5(0.7)$ & $0(0)$ & $0(0)$ & $0(0)$ & $21(3.0)$ & $0.03(0.00,0.05)$ \\
\hline Decompression illness & $661(93.2)$ & $26(3.7)$ & $5(0.7)$ & $0(0)$ & $0(0)$ & $17(2.4)$ & $0.2(0.1,0.3)$ \\
\hline Pneumothorax & $685(96.6)$ & $0(0)$ & $0(0)$ & $0(0)$ & $0(0)$ & $24(3.4)$ & $\cdots$ \\
\hline Arterial gas embolism & $687(96.9)$ & $0(0)$ & $0(0)$ & $0(0)$ & $0(0)$ & $22(3.1)$ & $\cdots$ \\
\hline
\end{tabular}

the mean number of dives performed was 261.7 (median, 150; range, 0-2000).

Table 2 describes the acute diving-related injuries reported. Most injuries resulted from barotrauma. The highest rates of injury were sustained from ear, sinus, and tooth "squeeze" problems $(53.5 \%, 36.7 \%$, and $11.4 \%$ of divers, respectively). These conditions, especially ear squeeze, were often sustained repeatedly. Middle and inner ear barotrauma had been sustained less frequently, but tympanic membrane (TM) and round/ oval window rupture were reported by $38(5.4 \%)$ and 8 $(1.1 \%)$ divers, respectively. Fourteen divers $(2.0 \%)$ had ruptured a TM on many occasions. Few divers reported conditions resulting from pulmonary barotrauma (subcutaneous emphysema, pneumothorax, and AGE). However, 31 divers (4.4\%) had suffered DCS. Table 3 describes other miscellaneous acute diving-related injuries reported. These injuries were varied but infrequent.

Sixteen divers $(2.3 \%)$ reported permanent disabilities following diving injuries. These disabilities and the contributing diving-related injuries are described in Table 4. Most disabilities were related to middle or inner ear damage (divers 1-10), and each of these divers suffering these injuries had a history of aural barotrauma. Only 4 divers (divers 11-14) reported disabilities following DCS; however, these 4 divers represented $12.9 \%$ of all divers with a history of DCS. The nature of the disabilities and contributing injuries reported by divers 15 and 16 was unspecified.

\section{Discussion}

The finding that most divers were middle-aged men who had logged a considerable number of dives over many years is consistent with a US study of experienced, rec- reational divers. ${ }^{13}$ The high socioeconomic class of most divers is consistent with their ability to continue participation in this relatively expensive sport.

It was expected that aural barotrauma would be the most common cause of injury, and this supports the finding of other researchers. ${ }^{14}$ In particular, ear squeeze had been experienced by more than half of the divers. Sinus squeeze was also common (one third of the divers), but tooth squeeze was not as common. One in 20 divers (5.4\%) reported a history of ruptured TMs. Inner ear

Table 3. Miscellaneous diving-related injuries reported

\begin{tabular}{lc}
\hline \multicolumn{1}{c}{ Injury } & $\begin{array}{c}\text { No. divers } \\
\text { reporting } \\
\text { this injury }\end{array}$ \\
\hline Headaches & 4 \\
Aspiration & 2 \\
Epistaxis & 2 \\
Vertigo & 1 \\
Syncope & 1 \\
Tinnitus & 1 \\
Eyesight difficulty-unspecified & 1 \\
Optic barotrauma-unspecified & 1 \\
Pulmonary embolus & 1 \\
Sinusitis & 1 \\
Ruptured sinus & 1 \\
Mastoiditis & 1 \\
Ear infection & 1 \\
Skin cuts & 1 \\
Sore knee & 1 \\
Bruising & 1 \\
Swollen feet & 1 \\
Swelling unspecified & 1 \\
&
\end{tabular}


Table 4. Permanent disabilities resulting from diving $(n=16)$

\begin{tabular}{rll}
\hline Diver & \multicolumn{1}{c}{ Nature of disability } & Diving-related injuries sustained by each diver (frequency in parentheses) \\
\hline 1 & Hearing loss & Ear squeeze (many), TM rupture (1), round/oval window rupture (1) \\
2 & Hearing loss & Ear squeeze (many) \\
3 & Hearing loss & Ear squeeze (1), TM rupture (1) \\
4 & Hearing loss & Ear squeeze (many), sinus squeeze (many) \\
5 & Hearing loss & TM rupture (1) \\
6 & Hearing loss and tinnitus & Ear squeeze (many), TM rupture (1), round/oval window rupture (1) \\
7 & Tinnitus & Ear squeeze (many), sinus squeeze (1) \\
8 & Tinnitus & Ear squeeze (3), sinus squeeze (3), round/oval window rupture (1) \\
9 & Scarring of TM & Ear squeeze (many), sinus squeeze (2) \\
10 & Scarring of inner ear & Ear squeeze (2) \\
11 & Nerve damage (unspecified) & Ear squeeze (3), sinus squeeze (3), DCS (1) \\
12 & Balance disturbance & DCS (1) \\
13 & Skin "hit" on back (itching) & DCS (1) \\
14 & Neck pain & DCS (1) \\
15 & Knee discomfort & $\ldots$ \\
16 & Infected ulcers & $\ldots$ \\
\hline
\end{tabular}

TM indicates tympanic membrane; DCS, decompression sickness.

barotrauma was much less common. It is somewhat surprising that those divers with TM and inner ear damage continue to dive and expose themselves to the potential for repeat injuries. However, evidence indicates that careful diving is permissible even after middle ear surgery $^{15}$ and inner ear barotrauma. ${ }^{16}$

Of concern is that 5 divers in our study reported subcutaneous emphysema. This condition is caused by pulmonary barotrauma with alveolar rupture. It is generally considered a contraindication to further diving, as the resultant scarring is thought to predispose the diver to a greater risk of further alveolar rupture and possibly AGE. It is not known whether these 5 divers received advice regarding this danger and, if so, chose to heed or ignore it.

The rate of DCS ( 0.2 per 1000 dives or 1 case per 5082 dives) is consistent with that reported by the Diver Alert Network (1 case per 5000-10 000 dives). ${ }^{2}$ However, our rate is likely to be an underestimation of the true incidence of DCS, as it is likely that some divers stopped diving after an episode of DCS and were not available for the survey.

The miscellaneous injuries described in Table 3 vary considerably. This list was developed from an open-ended question inviting divers to note any other injuries suffered; however, it is likely to significantly underestimate the many minor injuries sustained frequently by recreational divers. For example, minor skin cuts and ear infections (otitis externa) are often sustained.

Of particular importance are the chronic disabilities reported. Although it is encouraging that only 16 divers reported such disabilities, 10 of the 16 divers reported an aural problem (hearing loss, tinnitus, or aural scarring). As would be expected, each of these divers had also experienced (often repeatedly) aural barotrauma. In a review, Spira ${ }^{4}$ reports that the middle ear is the most common part of the body to be affected by barotrauma, occurring in $30 \%$ to $60 \%$ of divers, and that hearing loss and tinnitus may result.

The pathology related to this hearing loss and tinnitus is not well understood. One cause of aural symptoms may be repeated minor barotrauma. In a study of men undergoing a scuba-training program, Paaske et al ${ }^{17}$ reported that the strain exerted on the TM and middle ear from barotrauma resulted in reversible impairment of the recoiling capacity of the TM elastic fibrils and concluded that, if barotrauma continued, these changes could be irreversible and result in permanent changes in TM compliance. Another cause of chronic aural symptoms may be the scarring that results from overt rupture of the TM or the round or oval windows. Additionally, it is conceivable that subclinical DCS with localized CNS degeneration is a mechanism of aural symptoms.

The divers in this study were asked to report only permanent disabilities resulting from diving. In a separate arm of this study, ${ }^{18}$ the Australian cohort was asked to report medical conditions that resulted from all or unknown causes, not only diving. In this separate arm, an unexpectedly high prevalence of aural disorders was found: $12.2 \%$ and $23.4 \%$ of divers reported past or present hearing loss and tinnitus, respectively. ${ }^{18}$ Hence, while our study describes $10(1.4 \%)$ divers with aural 
problems they attributed to diving, many more are suffering (or have suffered) these conditions without attributing them to diving. It is postulated that repeated minor barotrauma, subclinical DCS, or both are the cause of these symptoms.

If diving is, indeed, the cause of these aural symptoms, the nature of the aural injury needs to be clarified. Clearly, barotrauma is the most likely cause; however, inner ear DCS may also present with hearing loss, tinnitus, vertigo, and nausea. ${ }^{4}$ Clinically, symptoms of hearing loss and tinnitus due to either barotrauma or DCS may be ambiguous. ${ }^{4,8}$ As mentioned, evidence indicates that CNS degeneration (secondary to subclinical DCS) is demonstrable among experienced divers. ${ }^{9-11}$ Hence, it is conceivable that such subclinical CNS DCS might also be a cause of the aural symptoms reported.

This study has several limitations related to selection bias. First, we surveyed experienced diving club members who may not have been representative of novice divers (who tend to be younger) or of experienced divers in general. Second, it is possible that the respondents represented the "survivors" among the diving population. That is, divers who had suffered significant morbidity from diving injuries (eg, DCS and AGE) or repeated injuries (eg, aural barotrauma) may have given up the sport. Hence, in this respect, our results are likely to underestimate some injury rates. Third, because participation in the study was voluntary, it is possible that the sample was skewed toward divers who had sustained a diving injury; thus, some injury rates may be overestimated. Finally, even though our sample size was moderate, it represents only a small proportion of active recreational divers in Australia and the United States. Unfortunately, we were unable to obtain a response rate in this study because very few club representatives reported the number of members at their meeting.

The rates of injury reported are, at best, estimates. It is likely that recall bias contributed to an underestimation of injury rates. The divers were asked to report injuries suffered over the duration of their diving careers, many of which were lengthy. Minor injuries (eg, ear squeeze) causing little inconvenience are more likely to be forgotten than serious injuries (eg, DCS). This may result in differential underreporting. Hence, the rates of serious injury reported may be more accurate. Also, the injury rates are based on self-reporting by the divers, and the accuracy of the injury diagnosis may be suspect. Further underestimation of some injury rates will have resulted from classifying divers who reported an acute injury "many times" as having suffered that injury 4 times only. Some data were missing. Small numbers of divers failed to report whether or not they had suffered an acute injury (Table 2). This may have caused an un- derestimation of injury rates. Nine divers failed to report the number of dives performed, and 53 divers who had performed more than 1000 dives were deemed to have undertaken 999 dives. This underreporting of dives is likely to have contributed to an overestimation of injury rates.

A prospective cohort study is needed to more accurately determine the rates of acute diving-related injuries. We recommend studies that use a modified diving logbook. This log would be designed to gather data relating to clearly defined acute diving injuries and would assist in minimizing recall bias and inaccuracies in numerator and denominator data used in the calculation of injury rates.

This study suggests that chronic disabilities directly attributable to diving are uncommon. Although few of the aural symptoms experienced by the Australian cohort $^{18}$ were attributed to diving, these symptoms may have been due to repeated diving, and further research is needed in this area. In particular, studies comparing the hearing of experienced divers with that of a nondiving control group are required. Such studies will lead to a more accurate determination of the prevalence of hearing problems among divers.

\section{CONCLUSION}

Recreational scuba divers suffer a variety of acute diving-related injuries. The most common injuries reported in this study resulted from barotrauma to the ears, sinuses, and teeth. Chronic disabilities attributed to diving largely involved hearing loss and tinnitus. However, evidence suggests that diving may contribute to more aural problems than previously thought. Further research is needed to accurately determine the prevalence and cause of aural problems among experienced divers.

\section{Acknowledgment}

The authors wish to acknowledge the support of the Pittsburgh Emergency Medicine Foundation, who funded the study.

\section{References}

1. Edmonds C. Medical standards for recreational divers. In: Edmonds C, Lowry C, Pennefather J, Walker R, eds. Diving and Subaquatic Medicine. 4th ed. London: Arnold Publishers; 2002:533-552.

2. Diver Alert Network. Report on Decompression Illness and Diving Fatalities. Durham, NC: Diver Alert Network; 2000 .

3. Morgan WP. Anxiety and panic in recreational scuba divers. Sports Med. 1995;20:398-421. 
4. Spira A. Diving and marine medicine review. Part II: diving diseases [review]. J Travel Med. 1999;6:180-198.

5. Elliott D. Why fitness? Who benefits from diver medical examinations? SPUMS J. 2000;30:206-209.

6. Edmonds $\mathrm{C}$. Why divers die: the facts and figures. In: Edmonds C, Lowry C, Pennefather J, Walker R, eds. Diving and Subaquatic Medicine. 4th ed. London: Arnold Publishers; 2002:473-490.

7. Edmonds C, Lowry C, Pennefather J, Walker R, eds. Diving and Subaquatic Medicine. 4th ed. London: Arnold Publishers; 2002.

8. Newton HB. Neurological complications of scuba diving. Am Fam Physician. 2001;63:2211-2218, 2225-2226.

9. Walker R, Edmonds C. Long-term effects of diving. In: Edmonds C, Lowry C, Pennefather J, Walker R, eds. Diving and Subaquatic Medicine. 4th ed. London: Arnold Publishers; 2002:457-464.

10. McQueen D, Kent G, Murrison A. Self-reported long-term effects of diving and decompression illness in recreational scuba divers. Br J Sports Med. 1994;28:101-104.

11. Reul J, Weis J, Jung A, Willmes K, Thron A. Central nervous system lesions and cervical disc herniations in amateur divers. Lancet. 1995;345:1403-1405.
12. Knauth M, Ries S, Pohimann S, et al. Cohort study of multiple brain lesions in sport divers: role of a patent foramen ovale. Br Med J. 1997;314:701-705.

13. Hansen E, Fleisher J, Jackson R, et al. Demographics and illness prevalence in recreational scuba divers. Available at: http://www.diversalertnetwork.org/medical/articles/. Accessed October 25, 2002.

14. Green SM, Rothrock SG, Hummel CB, Green EA. Incidence and severity of middle ear barotrauma in recreational scuba diving. J Wilderness Med. 1993;4:270-280.

15. House JW, Toh EH, Perez A. Diving after stapedectomy: clinical experience and recommendations. Otolaryngol Head Neck Surg. 2001;125:356-360.

16. Parell GJ, Becker GD. Inner ear barotrauma in scuba divers. A long-term follow-up after continued diving. Arch Otolaryngol Head Neck Surg. 1993;119:455-457.

17. Paaske PB, Staunstrup HN, Malling B, Knudsen L. Impedance measurement in divers during a scuba-diving training programme. Clin Otolaryngol. 1991;16:145-148.

18. Taylor DMcD, O'Toole KS, Ryan CM. Experienced, recreational scuba divers in Australia continue to dive despite medical contra-indications. Wilderness Environ Med. 2002;13:187-193. 